\title{
Acamprosate in the treatment of alcoholism: a budget impact analysis for the National Health Service in Italy
}

This article was published in the following Dove Press journal:

Substance Abuse and Rehabilitation

16 July 2012

Number of times this article has been viewed

\author{
Giorgio L Colombo ${ }^{1,2}$ \\ Sergio Di Matteo ${ }^{2}$ \\ Giacomo Bruno² \\ 'Department of Drug Sciences, School \\ of Pharmacy, University of Pavia, \\ Pavia, Italy; ${ }^{2}$ S.A.V.E. - Studi Analisi \\ Valutazioni Economiche, Milan, Italy
}

Objective: Alcohol dependence is a common condition associated with high direct and indirect health care costs. The purpose of this analysis was to estimate the economic consequences of acamprosate used as adjuvant therapy in the treatment of alcoholism, defining a budget impact analysis (BIA) from the point of view of the Italian National Health Service (NHS).

Methods: We developed a model of disease evolution related to alcoholism using data from the PRAMA study. The hypothetical population included in the decision model was obtained from data from the Ministry of Health. We compared the following treatment strategies: no treatment, standard care (psychotherapy), sodium oxybate (sodium salt-4-hydroxybutyric acid), and acamprosate. The time horizon of the model was 10 years. The costs were evaluated from the NHS perspective.

Results: We simulated the path for 69,348 patients treated at the outpatient clinics of the Addiction Services (SerT), and 38,911 patients discharged from hospital. Patients in the acamprosate group had lower alcohol-related events, with a reduction of the total cost. The BIA shows that the increase in the use of acamprosate was associated with a progressive decrease of total costs, calculated as the sum of the diagnosis-related groups (DRG), rehabilitation, and drug costs. The increasing use of acamprosate instead of standard care and sodium oxybate would generate cost savings up to over $€ 6$ million over 10 years of simulation.

Conclusion: The estimates in the model are based on hypothetical situations; the assumptions of the model as well as their specific impact on treatment effect estimations and clinical implications should be validated in real life. Public health care authorities would benefit from mathematical models designed to estimate the future burden of alcohol dependence together with the impact of treatment and the potential to reduce the incidence and progression of this condition, and the costs of its complications.

Keywords: alcohol dependence, acamprosate, budget impact analysis, economic evaluation

\section{Introduction}

Alcohol dependence is a common condition associated with high direct and indirect health care costs. ${ }^{1}$ Given the prevalence of alcohol-related health problems, the total costs attributable to alcohol abuse disorders represent a significant proportion of national health care spending in Europe. ${ }^{2-4} \mathrm{~A}$ recent study from France has suggested that costs owing to alcoholism correspond to $\sim 1 \%$ of the gross national product, ${ }^{5}$ while in Finland, direct health costs alone represent $\sim 0.6 \%$ of the gross domestic product, and the total health costs may reach $4.3 \%$ of the gross domestic product. ${ }^{6}$ The economic aspects of alcoholism have become increasingly important, due to rising health care costs, limited health care resources, and the potential to reduce the condition incidence
Correspondence: Giorgio L Colombo S.A.V.E. - Studi Analisi Valutazioni Economiche, Via Previati, 74 20149 Milan, Italy

$\mathrm{Tel}+3902485$ I 9230

Fax +3902 73960369

Email giorgio.colombo@unipv.it 
and progression and the cost of complications if alcohol misuse can be minimized. ${ }^{7}$ Thus, any treatment program that interrupts the course of chronic alcohol dependence or reduces its severity may result in significant cost savings for society. Alcohol dependence can be treated to some extent with psychosocial intervention programs or pharmacotherapy with abstinence-promoting drugs, or both.

In the scientific literature, acamprosate, administered in addition to standard care (eg, psychosocial counseling and behavioral treatment), significantly reduced relapse rates, as confirmed by several controlled clinical trials in Western European countries. ${ }^{8-13}$ However, in spite of the large amount of information available on the economic costs of alcohol dependence, as well as extensive public awareness of this, there are little data on the costs and savings associated with the different detoxification and rehabilitation strategies used in the management of alcohol dependence. ${ }^{1,7,14}$ The purpose of this analysis was to estimate the economic consequences of acamprosate used as adjuvant therapy in the treatment of alcoholism, defining a budget impact analysis (BIA) from the point of view of the Italian National Health Service (NHS).

\section{Methods}

\section{Structure of the model}

We outlined an economic evaluation of four treatment strategies of alcohol dependence, with the aim of carrying out a BIA of these strategies for the Italian NHS. ${ }^{15,16}$ We therefore developed an evolution model of the diseases linked with alcoholism with their respective occurrence probabilities, based on the study by Schädlich and Brecht ${ }^{2}$ through data from the PRAMA study. ${ }^{12}$ In this double-blind study, after a short detoxification period, patients were randomized to placebo vs acamprosate in addition to psychological support, for 48 weeks. Patients were then followed up with no specific drug treatment for alcohol dependence for another 48 weeks. All patients included in the PRAMA trial had an alcoholism problem for a mean duration of 10 years. In order to enter the study, patients had to be completely abstinent for a minimum of 14 days to a maximum of 28 days, in accordance with the hospital detoxification period. The treatment consisted of counseling or psychotherapy, according to the routine practice of the centers, with the addition of the drug or placebo as adjuvant therapy.

The evolution model of the diseases linked with alcoholism involves a three-branch, decision-tree structure (Figure 1); the occurrence probabilities of the comorbidities of alcoholism were then integrated with efficacy data from the literature, with data on drug therapies and with the costs of the treatment and management of alcohol-related complications. The four treatment strategies compared are: no treatment, psychological support alone (standard care), sodium oxybate, and acamprosate. The model simulates the path which the hypothetical cohort of initial patients would follow, based on each treatment considered. The study supposes that abstinent patients do not experience events related to alcohol abuse, and was performed on a 10 -year time frame.

\section{Reference population}

Since it is impossible to precisely determine the number of alcohol-dependent patients, the initial populations included in the decision model were taken from data from the Ministry of Health and subdivided per patients treated at the outpatient clinics of the Servizi per le Tossicodipendenze (SerT, Addiction Services) ${ }^{17}$ and per patients treated in the Italian hospitals. The alcohol-dependent patient population consisted of: 69,348 (alcohol-dependent patients referred to SerT centers per each Italian region in the year 2008) and

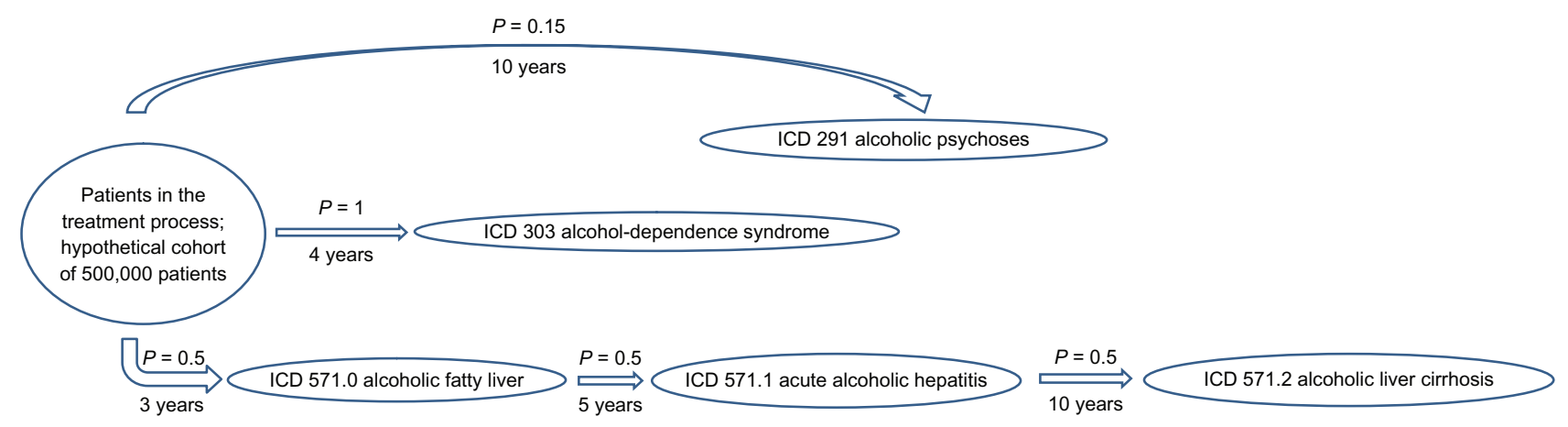

Figure I Structure of the model.

Copyright $@$ 1998, Adis International. Schädlich PK, Brecht JG. The cost effectiveness of acamprosate in the treatment of alcoholism in Germany. Economic evaluation of the Prevention of Relapse with acamprosate in the Management of Alcoholism (PRAMA) Study. Pharmacoeconomics. 1998;13:719-730. ${ }^{2}$

Abbreviations: ICD, International Classification of Diseases. 
Table I Abstained and relapsed patients

\begin{tabular}{lll}
\hline & Patients abstained & Patients relapsed \\
\hline No treatment & $0.0 \%$ & $100.0 \%$ \\
Standard care & $4.8 \%$ & $95.2 \%$ \\
Sodium oxybate & $16.8 \%$ & $83.2 \%$ \\
Acamprosato & $19.4 \%$ & $80.6 \%$ \\
\hline
\end{tabular}

Note: Annual percentages used in the model. ${ }^{12,19}$

38,911 (number of discharged patients for alcohol-related pathologies from Italian hospitals in the year 2005). ${ }^{17}$

The number of patients referred to the SerT clinics has been shown to significantly and constantly grow over time: 58,574 (2007), 61,656 (2006), 56,234 (2005), and 53,914 (2004). The proposed model takes into account the "stratification" of alcohol-dependent patients referred to the SerT clinics, in particular: 40,707 patients treated with standard care, 20,804 treated with pharmacological support (specifically: 5879 with sodium oxybate, and 14,925 with other treatments), and lastly, 7837 hospitalizations. As for discharges, we took into account that 33,633 cases were conventional inpatient hospitalizations and 5278 were patients in day hospital regimens. ${ }^{18}$

\section{Source of efficacy data}

With the intention of obtaining comparable efficacy data, we carried out intention-to-treat analyses based on efficacy data from the literature. ${ }^{12,19}$ The results are shown in Table 1.

\section{Resource consumption and costs}

The management and rehabilitation costs were taken from the International Classification of Diseases (ICD IX CM): alcohol-induced mental disorders (ICD 291), alcoholdependence syndrome (ICD 303), and alcoholic liver damage unspecified (ICD 571.0-571.3).$^{20}$ Not all costs due to alcoholism (eg, indirect costs due to loss of productivity, costs incurred for road accidents, and crimes) were considered in these events. The analysis was carried out from the Italian NHS perspective using (DRG) fees from the national price list TUC 2010, ${ }^{21}$ such as health care costs for hospitalization and rehabilitation (Table 2). The cost values were then subjected to discounting using sensitivity analysis. ${ }^{22}$

The drug treatment costs were taken from the Italian Medicines Agency (AIFA) ${ }^{23}$ considering the selling price to the NHS, which came to $€ 14.91$ per pack of sodium oxybate and $€ 20.33$ per pack of acamprosate, on average (VAT excluded). The drug treatments with sodium oxybate and acamprosate are proportional to the patient's weight; the proposed model assumed that $80 \%$ of the subjects weighed over $60 \mathrm{~kg}$.

\section{Results}

Based on the proposed model, we simulated the paths of 69,348 patients from SerT clinics and 38,911 patients discharged from hospitals, with the following results. In the "no treatment" group, during the 10 years of simulation, all patients experienced alcohol-related complications. In the standard care group, because of the abstinent percentage $(4.8 \%)$, the number of patients entering the simulation model is lower, as is therefore the number of complications due to alcohol abuse. The recovery percentage significantly increases with sodium oxybate $(16.8 \%)$ and especially acamprosate (19.4\%), with the consequences shown in Table 3.

Total expenses, including management costs, rehabilitation costs, and drug costs, relating to each treatment considered in the study are reported in Figures 2 and 3.

Acamprosate was shown to be less costly both in the SerT arm and in the hospital discharge arm.

In order to quantify the economic impact on the NHS of the potential use of acamprosate in the treatment of alcohol-dependent patients, a budget impact anlaysis was carried out ${ }^{24}$ considering the number of alcohol-dependent

Table 2 DRG costs for alcohol-related diseases/rehabilitation costs for alcohol-related diseases

\begin{tabular}{|c|c|c|c|c|c|}
\hline & \multicolumn{2}{|l|}{ DRG } & \multicolumn{3}{|c|}{ National Tariff (TUC) } \\
\hline & Conventional & Day hospital & Conventional & & Day hospital \\
\hline \multirow[t]{2}{*}{ ICD 29I (alcohol-induced mental disorders) } & & & & Rehabilitation & \\
\hline & $€ \mathrm{€}, 983.53$ & $€|78.5|$ & $€ 204.63$ & & $€ I 63.70$ \\
\hline \multirow[t]{2}{*}{ ICD 303 (alcoholic liver damage unspecified) } & & & & Rehabilitation & \\
\hline & $€ \mathrm{€}, 983.53$ & $€|78.5|$ & $€ 204.63$ & & $€ 163.70$ \\
\hline \multirow[t]{2}{*}{ ICD 57 I.0 (alcoholic fatty liver) } & & & & Rehabilitation & \\
\hline & $€ \mathrm{I}, 943.97$ & $€ 274.95$ & $€ 204.63$ & & $€ 163.70$ \\
\hline \multirow[t]{2}{*}{ ICD 57I.I (acute alcoholic hepatitis) } & & & & Rehabilitation & \\
\hline & $€ 3,327.98$ & $€ 324.28$ & $€ 204.63$ & & $€ 163.70$ \\
\hline \multirow[t]{2}{*}{ ICD 57I.2 (alcoholic liver cirrhosis) } & & & & Rehabilitation & \\
\hline & $€ 3,327.98$ & $€ 324.28$ & $€ 204.63$ & & $€ 163.70$ \\
\hline
\end{tabular}

Health Ministry, Ministero della Salute. Available at: http://www.salute.gov.it/ricoveriOspedalieri/ric_informazioni/interrogad.jsp. Accessed November I, 201 I. ${ }^{18}$ Abbreviations: DRG, diagnosis-related group; ICD, International Classification of Disease; TUC, Tariffa Unica Convenzionale - National Tariff. 
Table 3 Number of alcohol-related complications (ICD) for patients from SerT clinics and for patients discharged from hospital

\begin{tabular}{|c|c|c|c|c|c|c|c|c|}
\hline & \multicolumn{4}{|l|}{ SerT } & \multicolumn{4}{|c|}{ Hospital discharge } \\
\hline & $\begin{array}{l}\text { No } \\
\text { treatment }\end{array}$ & $\begin{array}{l}\text { Standard } \\
\text { care }\end{array}$ & $\begin{array}{l}\text { Sodium } \\
\text { oxybate }\end{array}$ & Acamprosato & $\begin{array}{l}\text { No } \\
\text { treatment }\end{array}$ & $\begin{array}{l}\text { Standard } \\
\text { care }\end{array}$ & $\begin{array}{l}\text { Sodium } \\
\text { oxybate }\end{array}$ & Acamprosato \\
\hline ICD 29I & 10,402 & 9,903 & 8,655 & 8,384 & 5,837 & 5,556 & 4,856 & 4,704 \\
\hline ICD 303 & 69,348 & 66,019 & 57,698 & 55,894 & 38,911 & 37,043 & 32,374 & 31,362 \\
\hline ICD 57I.0 & 34,674 & 33,010 & 28,849 & 27,947 & 19,456 & 18,522 & 16,187 & $|5,68|$ \\
\hline ICD 57I.I & 17,337 & 16,505 & 14,424 & 13,974 & 9,728 & 9,261 & 8,093 & 7,841 \\
\hline ICD 57I.2 & 8,669 & 8,252 & 7,212 & 6,987 & 4,864 & 4,630 & 4,047 & 3,920 \\
\hline Total & 140,430 & 133,689 & I 16,838 & 113,186 & 78,795 & 75,013 & 65,557 & 63,509 \\
\hline
\end{tabular}

Abbreviations: ICD, International Classification of Diseases; SerT, Addiction service.

patients referring to SerT clinics (around 69,000), and considering that, based on data from the Health Ministry (17), $87.4 \%(40,707)$ of these are treated with the standard care method and $12.6 \%$ (5879) are treated with sodium oxybate. The budget impact analysis assumes an increasing use of acamprosate, simulating a progressive increase of drug use from $25 \%$ to $100 \%$ of the studied population.

In order to provide realistic estimates, the acamprosate increment is considered proportional among the patients treated with standard care and sodium oxybate. The results reported in Table 4 show how the increase in the use of acamprosate corresponds to a progressive decrease of the total costs (DRG for conventional hospitalization plus rehabilitation plus cost of the drug).
The obtained results allow us to quantify the potential saving (in millions of euros) that the NHS would obtain if the use of acamprosate were progressively increased (Figure 4). The decision to use acamprosate in increasing proportion instead of standard care and sodium oxybate would generate savings up to over $€ 6$ million (use of acamprosate on the whole studied population) over the simulation period.

\section{Discussion}

For several years, the Italian epidemiologic picture has shown trends that have triggered calls for the adoption of a "Piano Nazionale Alcol e Salute" (National Alcohol and Health Plan) and for the inclusion of alcohol in the prevention and health-promotion strategies described in the "Gua-

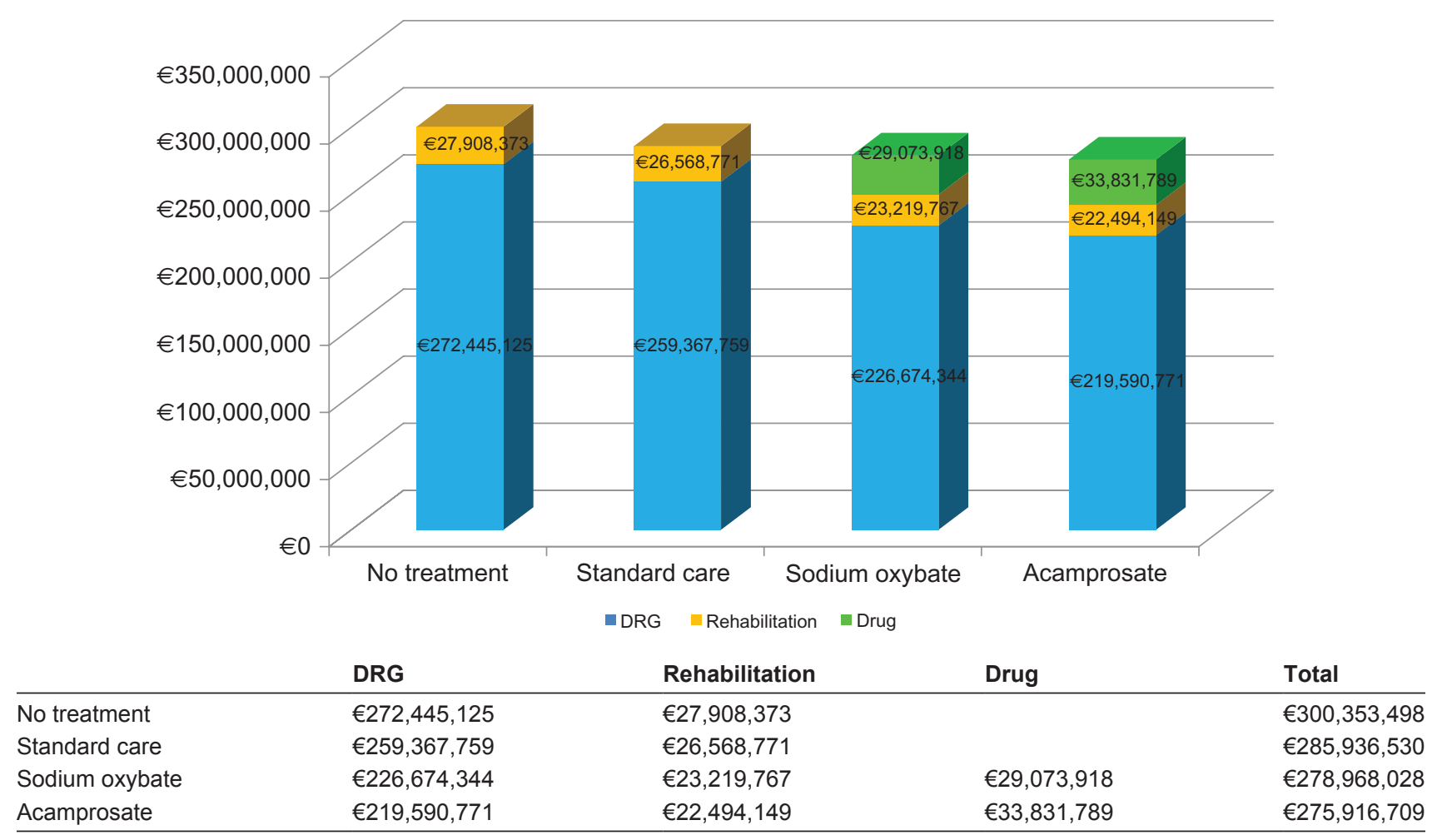

Figure 2 Total cost (hospital, rehabilitation, drugs) for SerT patients in the different treatment strategies. Abbreviations: DRG, diagnosis-related group; SerT, Addiction service. 


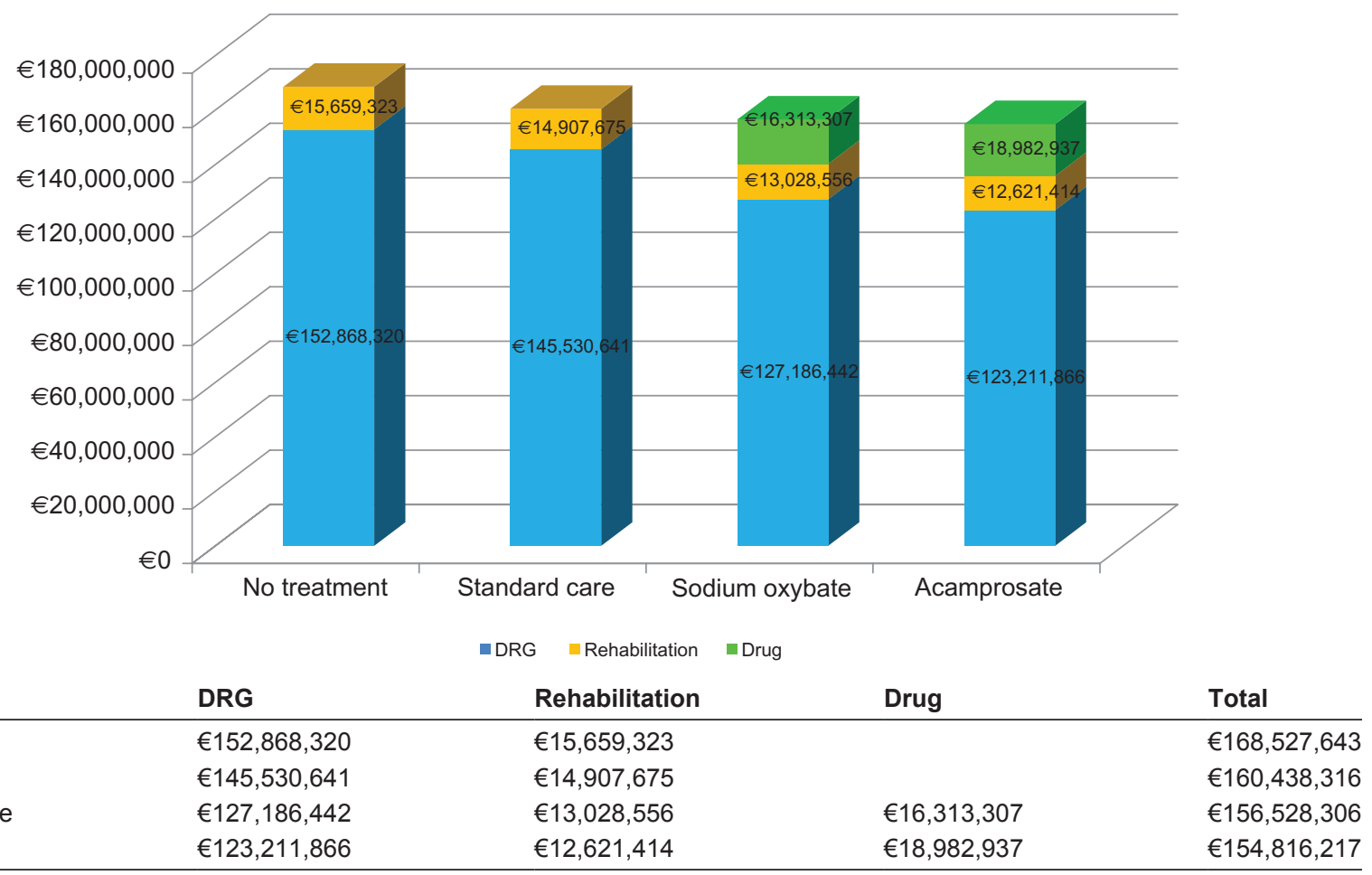

Figure 3 Total cost (hospital, rehabilitation, drugs) for hospital-discharged patients in the different treatment strategies. Abbreviation: DRG, diagnosis-related group.

dagnare Salute" (Gaining Health) program (Health Ministry Report on Law no 125). ${ }^{17}$ Despite these priorities defined by the Italian public authorities, the culture of drinking as a shared and approved social behavior (especially among the very young, the elderly, and women) increase the percentage of the people consuming alcohol and consequently associated health risk (Health Ministry Report on Law no 125). Moreover, in the context of limited health care resources, the possibility of reducing the incidence and progression of the costs of alcoholism complications is gaining more and more importance. The action of optimizing resources in this therapeutic area is primarily concentrated on direct health care costs due to hospitalization and on the rehabilitation treatment. ${ }^{17}$

Through the proposed decision-tree simulation model, this study has shown a net potential saving on direct health costs with the increased use of acamprosate in the treatment of alcohol dependence. Therapy with acamprosate has led to important clinical outcomes, both from the point of view of the Italian health care system (direct health costs) and from the point of view of the patients' health status. Acamprosate is a drug which acts on the glutamatergic neurotransmitter system involved in alcoholic intoxication mechanisms; a number of clinical studies have shown the efficacy of acamprosate in improving the mean duration of abstinence and in reducing the number of relapses and the quantity of consumed alcohol. ${ }^{25}$ The role of acamprosate, as in the case of other anticraving drugs, is centered on this last effect, aside from the abstinence-promoting action. ${ }^{26}$ Thanks to its metabolic profile, this drug is suited to the clinical population of alcoholics with liver disease (Child-Pugh Classes $\mathrm{A}$ and $\mathrm{B}$ ), as well as for use in multidrug therapies, with particular reference to psychiatric treatments and possible anti-craving combinations. Acamprosate, unlike other drugs proposed for the treatment of craving in alcohol-dependent patients, has an efficacy profile that increases with time,

Table 4 Results of the budget impact analysis

\begin{tabular}{|c|c|c|c|c|}
\hline & DRG & Rehabilitation & Drug & Total \\
\hline SerT & $€|7|, 464,236$ & $€ I 7,564,227$ & $€ 2,464,75 \mathrm{I}$ & $€|9|, 493,213$ \\
\hline $25 \%$ acamp. & $€ I 65,476,874$ & $€|6,950,90|$ & $€ 7,530,370$ & $€|89,958| 45$, \\
\hline 50\% acamp. & $€|59,489,5| 3$ & $€ 16,337,576$ & $€ 12,595,989$ & $€ 188,423,077$ \\
\hline 75\% acamp. & $€|53,502| 5 \mid$, & $€ I 5,724,250$ & $€|7,66|, 608$ & $€ \mid 86,888,009$ \\
\hline I00\% acamp. & $€|47,5| 4,790$ & $€ I 5,110,925$ & $€ 22,727,227$ & $€|85,352,94|$ \\
\hline
\end{tabular}

Abbreviations: acamp, acamprosate; DRG, diagnosis-related group; SerT, Addiction service. 


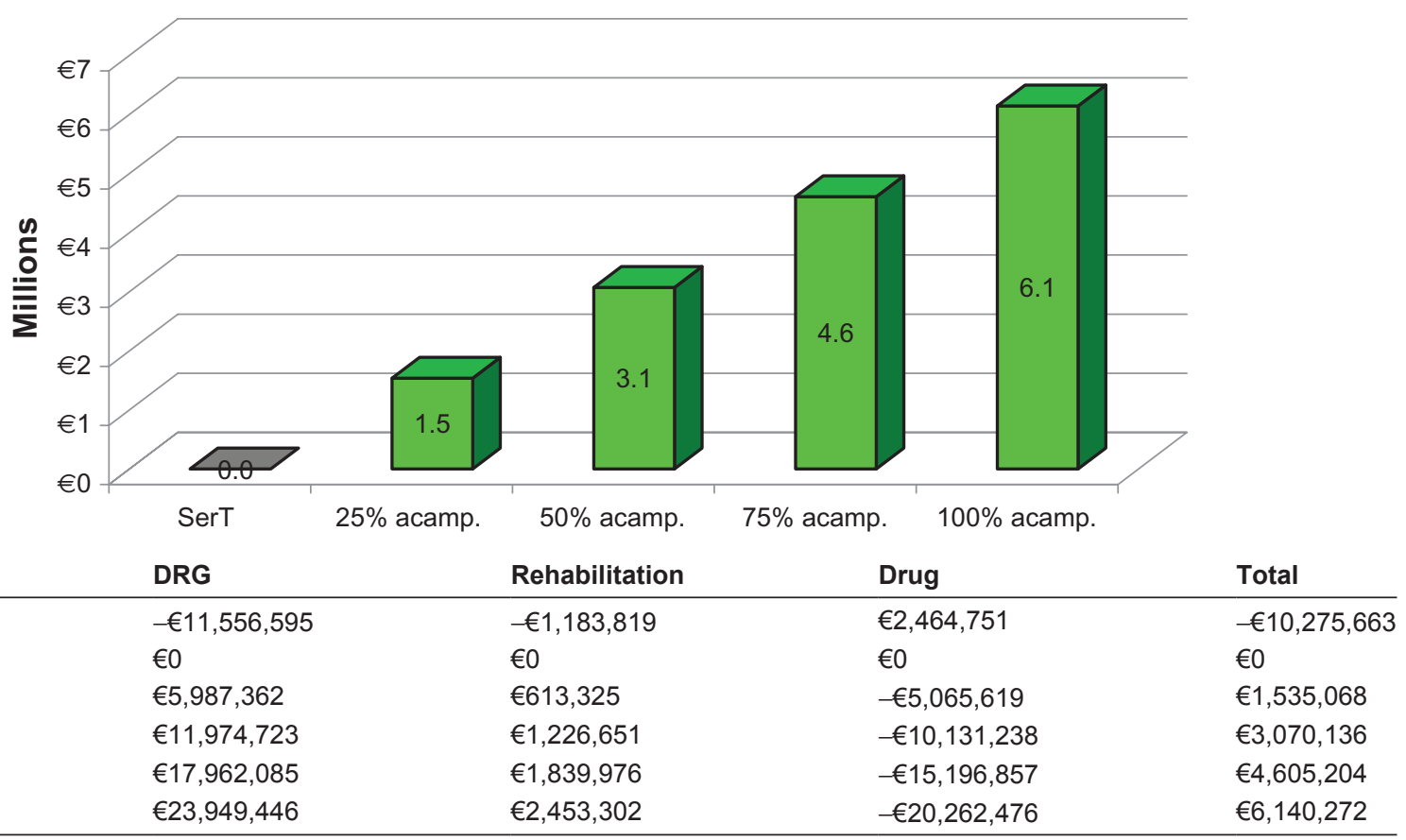

Figure 4 Budget impact analysis results: simulation of potential saving (10-year time horizon). Abbreviations: DRG, diagnosis-related group; acamp, acamprosate; SerT, Addiction service.

although it may not be immediately apparent, and a neuroprotective action that can be crucial in delaying alcohol-related brain damage, even in partial or late responders. ${ }^{25}$

Based on the design of the PRAMA study ${ }^{12}$ and on the simulation proposed, ${ }^{2}$ and adapted to the Italian situation, we can conclude that adjuvant therapy with acamprosate could result in a net saving of resources for the Italian NHS.

This study has some limitations, the most important of which concerns the quality of data entered into the model: parameters such as efficacy, for example, are based on data analysis with a limited time frame ( 2 years) and hence may be inadequate for modeling the treatment of a chronic disease for a longer time. The estimates are also based on hypothetical situation, not in real life. Moreover, the proposed model was structured as a decision-tree model which does not include possible relapses of the treated patients, as in the Markov simulation. ${ }^{7,14}$ This might partially overestimate the effects of the drug therapy, which should be verified in any case in real practice. Furthermore, our evaluation only considered direct health care costs, and not the production losses that alcohol dependency generates on the economic system as a whole; however, the inclusion of these indirect costs would have increased the results of our simulation in favor of the acamprosate strategy. Lastly, in spite of the fact that patients referring to the SerT clinics have increased with time, the reference population used might only represent a small proportion of those who would need a specific treatment in Italy at that particular moment. It is highly likely that alcoholics are "late" in contacting health care providers - in many cases, they wait until damage has become evident in the form of diseases or after traumatic events, and they are unlikely to contact the SerT clinics, which are more easily associated with the treatment of illegal substance abuse. Finally, it should be noted that the proposed extension of this simulation into public policy must be confirmed in clinical practice; specific impact on treatment effect estimations and clinical implications for different population groups should be evaluated in practice.

In spite of these limitations, the proposed study appears to be in line with other international studies on the same subject, ${ }^{27}$ which confirms the rationality of the adopted assumptions and the limits of the obtained results. To conclude, it is worth noting that the developed model is a dynamic instrument that can be adapted to various health care settings (overall in chronic disease) in that it can be run using different input data (ie, efficacy, cost, and epidemiology). ${ }^{28}$ By allowing simulations of different scenarios, it represents an invaluable tool for policy makers and health care professionals to make short- and long-term cost projections and thus evaluate their impact on the available budget. 


\section{Acknowledgment/disclosure}

This research was supported by MerckSerono Spa, Rome, Italy. Giorgio L Colombo, Sergio Di Matteo, and Giacomo Bruno (of S.A.V.E. Milan, Italy) are researchers of independent organizations, and maintained independent scientific control over the study, including data analysis and interpretation of final results. The authors report no conflicts of interest in this work.

\section{References}

1. Rehm J, Mathers C, Popova S, Thavorncharoensap M, Teerawattananon Y, Patra J. Global burden of disease and injury and economic cost attributable to alcohol use and alcohol-use disorders. Lancet. 2009; 373:2223-2233.

2. Schädlich PK, Brecht JG. The cost effectiveness of acamprosate in the treatment of alcoholism in Germany. Economic evaluation of the Prevention of Relapse with acamprosate in the Management of Alcoholism (PRAMA) Study. Pharmacoeconomics. 1998;13: 719-730

3. Brecht JG, Poldrugo F, Schädlich PK. Alcoholism: the cost of illness in the Federal Republic of Germany. Pharmacoeconomics. 1996;10: 484-493.

4. Holder HD, Hallan JB. Impact of alcoholism treatment on total health care costs: a six year study. Adv Alcohol Subst Abuse. 1986;6:1-15.

5. Reynaud M, Gaudin-Colombel AF, Le Pen C. Two methods of estimating health costs linked to alcoholism in France (with a note on social costs). Alcohol Alcohol. 2001;36:89-95.

6. Hein R, Salomaa J. What are the costs of substance abuse? Alcohol and drugs. Alcologia. 1999;11:135-143.

7. Palmer AJ, Neeser K, Weiss C, Brandt A, Comte S, Fox M. The longterm cost effectiveness of improving alcohol abstinence with adjuvant acamprosate. Alcohol Alcohol. 2000;35:478-492.

8. Littleton J. Acamprosate in alcohol dependence: how does it work? Addiction. 1995;90:1179-1188.

9. Paille FM, Guelfi JD, Perkins AC, Royer RJ, Steru L, Parot P. Doubleblind randomized multicentre trial of Acamprosate in maintaining abstinence from alcohol. Alcohol. 1995;30:239-247.

10. Aubin HJ, Lehert P, Beaupère B, et al. Tolerability of the combination of Acamprosate with drugs used to prevent alcohol withdrawal syndrome. Alcoholism. 1995;31:25-38.

11. Chick J. Acamprosate as an aid in the treatment of alcoholism. Alcohol. 1995;30:785-787.

12. Sass H, Soyka M, Mann K, Zieglgänsberger W. Relapse prevention by Acamprosate: results from a placebo-controlled study on alcohol dependence. Arch Gen Psychiatry. 1996;53:673-680.

13. Withworth AB, Fischer F, Lesch OM, et al. Comparison of Acamprosate and placebo in long-term treatment of alcohol dependence. Lancet. 1996;347:1438-1442.
14. Annemans L, Vanoverbeke N, Tecco J, D’Hooghe D. Economic evaluation of Campral (Acamprosate) compared to placebo in maintaining abstinence in alcohol-dependent patients. Eur Addict Res. 2000;6:71-78.

15. Drummond MF, O’Brien BJ, Stoddart GL, Torrange GW. Methods for the Economic Evaluation of Health Care Programs, 3rd ed. New York, NY: Oxford University Press; 2006.

16. Italian Health Economics Association - Associazione Italiana di Economia Sanitaria (AIES) Italian Guidelines proposal on how to conduct economic evaluation studies of health programs. Pharmacoeconomics Italian Research Articles. 2009;11:83-93. Italian.

17. Health Ministry, Relazione del Ministro della Salute al Parlamento sugli interventi realizzati ai sensi della Legge 30.03.2001 n. 125 'Legge Quadro in materia di alcol e problemi alcolcorrelati’, December 13, 2010. Available at: www.salute.gov.it/imgs/C_17_pubblicazioni_1451_allegato. pdf. Accessed November 1, 2011.

18. Health Ministry, Ministero della Salute. Available at: http://www.salute. gov.it/ricoveriOspedalieri/ric_codice/default.jsp. Accessed November 1, 2011.

19. Addolorato G, Castelli E, Stefanini GF, et al. An open multicentric study evaluating 4-hydroxybutyric acid sodium salt in the mediumterm treatment of 179 alcohol dependent subjects. Alcohol. 1996;31: 341-345.

20. ISTAT, National Institute of Statistic 'Classificazione delle malattie, traumatismi e cause di morte', 2010.

21. Tariffa Unica Convenzionale (TUC) per le prestazioni di assistenza ospedaliera, regole e tariffe valide per l'anno 2009 secondo CMS-DRG Versione 24, Conferenza delle Regioni e delle Province autonome 1O/014/CR10a/C7. DRG 206.

22. Coyle D, Tolley K. Discounting of health benefits in the pharmacoeconomic analysis of drug therapies. an issue for debate? Pharmacoeconomics. 1992;2:153-162.

23. AIFA, Agenzia Italiana del Farmaco - Italian Medicines Agency, List of marketed medicines. Available at: http://farmaco.agenziafarmaco.it/ index.php. Accessed November 1, 2011.

24. Simoens S. Health economic assessment: a methodological primer. Int J Environ Res Public Health. 2009;6:2950-2966.

25. Rugani F, Pacini M, Bacciardi S, Rovai L, Maremmani AGI, Maremmani I. 'Modalità vecchie e nuove dell'utilizzo di acamprosato'. MDD. 2011;4:59-72. Italian.

26. Wilde MI, Goa KL. Management of alcohol dependence after detoxification: the potential role of Acamprosate. Dis Manage Health Outcomes. 1998;3:35-46.

27. Barbosa C, Godfrey C, Parrott S. Methodological assessment of economic evaluations of alcohol treatment: what is missing? Alcohol Alcohol. 2010;45:53-63.

28. Colombo GL, Gaeta GB, Viganò M, Di Matteo S. A cost-effectiveness analysis of different therapies in patients with chronic hepatitis B in Italy. Clinicoecon Outcomes Res. 2011;3:37-46.

Substance Abuse and Rehabilitation

\section{Publish your work in this journal}

Substance Abuse and Rehabilitation is an international, peer-reviewed, open access journal publishing original research, case reports, editorials, reviews and commentaries on all areas of addiction and substance abuse and options for treatment and rehabilitation. The manuscript management system is completely online and includes a very quick and fair 